\title{
SISTEM PAKAR DIAGNOSA KERUSAKAN KENDARAAN PADA MOBIL WULING CONFERO S MENGGUNAKAN METODE CERTAINTY FACTOR
}

\author{
Kristyanto Nugroho ${ }^{1}$, Sumiati ${ }^{2}$ \\ 1,2 Jurusan Teknik Informatika Fakultas Teknologi Informasi Universitas Serang Raya \\ Jln. Raya Cilegon Serang - Drangong Kota Serang \\ ${ }^{1}$ noekris70@gmail.com \\ ${ }^{2}$ sumiati82@yahoo.com
}

\begin{abstract}
Abstrak - Wuling Confero S adalah produk mobil yang baru memulai pemasarannya di Indonesia yang diproduksi oleh PT SGMW Motor Indonesia, semakin hari pemilik mobil Wuling Confero S semakin meningkat. Namun banyak dari pemilik kendaraan yang kurang memiliki pengetahuan mengenai otomotif khusunya dalam hal perawatan dan perbaikan kendaraan. Terkadang ada kerusakan yang masih bisa ditangani sendiri oleh pemilik kendaraan namaun pemilik kendaraan lebih memiih mempercayakan kepada teknisi dalam menyelesaikan kerusakan yang terjadi padakendaraannya.Dari sisi mekanik, setiap mekanik tentu memiliki pengalaman dan kemampuan yang berbeda beda dalam menyelasaikan masalah kerusakan yang terjadi pada kendaraan, terutama untuk mekanik yang masih baru. Penelitian ini bertujuan untuk membuat sistem pakar diagnosa kerusakan mobil. Hal ini berguna untuk membantu pengendara mendeteksi dini kerusakan mobil serta memberikan informasi tentang tips untuk perawatan kendaraannya. Dalam proses perhitungannya digunakan metode certainty factor. Dengan menerapkan metode certainty factor untuk perhitungan kemungkinan kerusakan berdasarkan gejala yang dipilih user maka user akan menerima hasil berupa kemungkinan terbesar kerusakan yang terjadi sehingga user bisa mengetahui apa yang rusak padakendaraanya.
\end{abstract}

Kata Kunci : Certainty Factor, Sistem Pakar, Diagnosa Kerusakan Wuling Confero S

\section{PENDAHULUAN}

Wuling Motors adalah sebuah pabrikan yang berasal dari Tiongkok, pengguna mobil Wuling diIndonesia cukup banyak namun tidak semua pengguna tersebut mengerti bagaimana merawat kendaraanya, kebanyakan dari pengguna kendaraan hanya mengerti cara memakainya tanpa memperhatikan cara perawatannya. Padahal dengan melakukan perawatan dapat mengurangi resiko kerusakan pada mobil .

Selain untuk pengendara, bagi mekanik ketidaksamaan penguasaan pengetahuan dan pengalaman masing-masing mekanik membuat antara mekanik yang satu dengan lainnya hanya menerka-nerkasaja kerusakan yang terjadi pada mobil tersebut,banyak teknisi yang terkadang mengalami kesulitan dalam mendiagnosa suatu kerusakan pada kendaraan terutama untuk kalangan teknisi baru .

Oleh karena banyak orang yang tidak mengerti tentang mesin mobil maka penelitian tentang sistem pakar diagnosa kerusakan mobil ini sangat diperlukan. Hal ini berguna untuk membantu pengendara mendeteksi dini kerusakan mobil serta memberikan informasi tentang tips untuk perawatan kendaraannya. Dalam proses perhitungannya digunakan metode certainty factor.
Certainty Factor merupakan salah satu teknik yang digunakan untuk mengatasi ketidakpastian dalam pengambilan keputusan. Dengan menerapkan metode certainty factor untuk perhitungan kemungkinan kerusakan berdasarkan gejala yang dipilih user maka user akan menerima hasil berupa kemungkinan terbesar kerusakan yang terjadi sehingga user bisa mengetahui apa yang rusak pada kendaraanya. Hasil perhitungan ditampilkan berupa persentase kerusakan yang dihitung berdasarkan nilai MB dan MD yang telah ditetapkan oleh pakar .

Aplikasi sistem pakar menggunakan metode Certainty Factor ini tidak berarti menggantikan mekanik atau pakar mobil, tetapi hanya membantu dalam mengkonfirmasikan keputusannya dan mempermudah dalam pengambilan keputusan, karena mungkin bisa terdapat banyak alternatif yang harus dipilih secara tepat. Pada jurnal tersebut juga penelitian terbatas hanya untuk mendiagnosa kerusakan pada bagian mesin saja.

Diharapkan dengan diadakannya penelitian ini bisa menghasilkan suatu sistem pakar yang bisa digunakan untuk mendiagnosa kerusakan pada mobil Wuling Confero $S$ baik kerusakan dibagian mesin dan bagian bagian lainnyasehingga bisa membantu pengguna dalam mengetahui permasalahan yang 
terjadi pada kendaraannya jika suatu waktu terjadi kendala.

\section{Metodologi PEnelitian}

\section{A. Model Pengembangan Sistem Informasi}

Model pengembangan sistem informasi yang digunakan dalam penellitian ini adalah dengan menggunakan model waterfall. Metode air terjun atau yang sering disebut metode waterfall sering dinamakan siklus hidup klasik (classic life cycle), dimana hal ini menggambarkan pendekatan yang sistematis dan juga berurutan pada pengembangan perangkat lunak, dimulai dengan spesifikasi kebutuhan pengguna lalu berlanjut melalui tahapan-tahapan perencanaan (planning), permodelan (modeling), konstruksi (construction), serta penyerahan sistem ke para pelanggan/pengguna (deployment), yang diakhiri dengan dukungan pada perangkat lunak lengkap yang dihasilkan. Tahapan metode waterfall dapat dilihat pada gambar di bawah ini

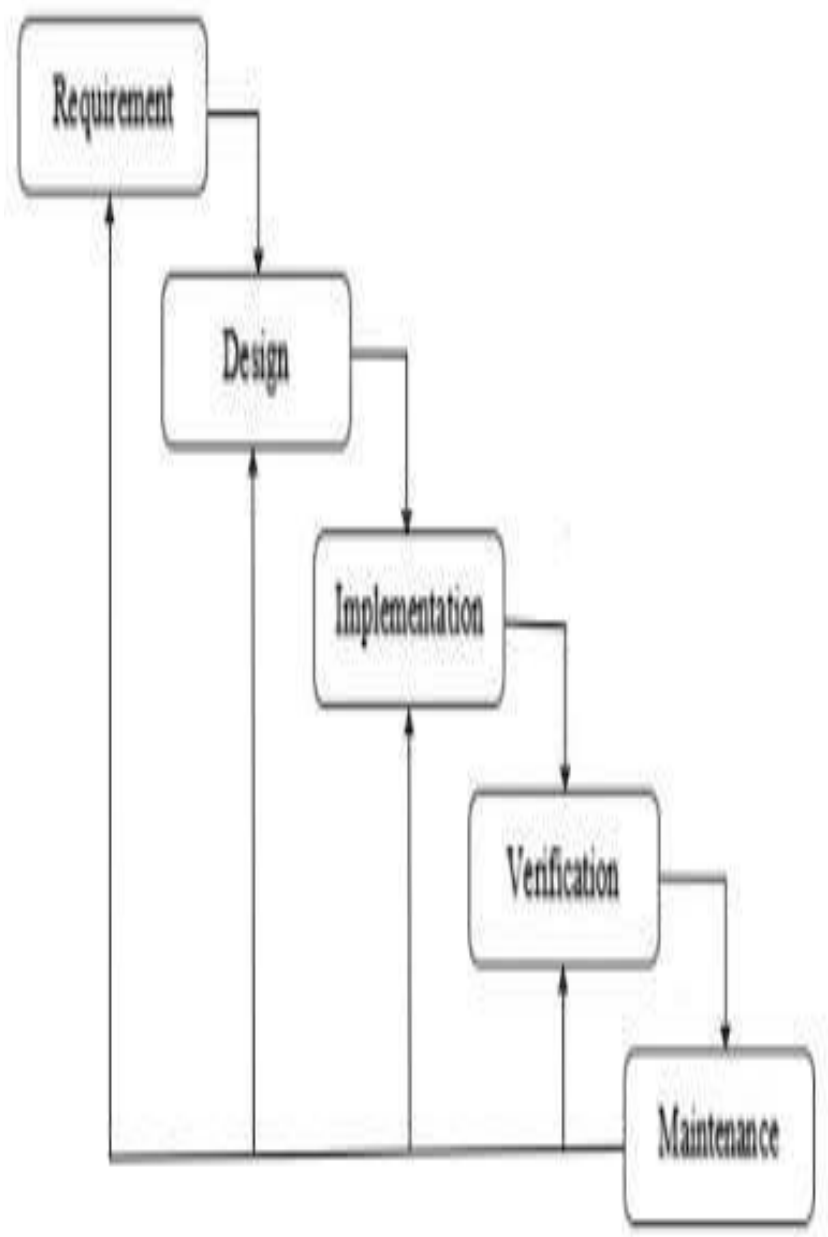

Gambar 1. Tahapan Model Waterfall

\section{Metode Pengumpulan Data}

Metode pengumpulan data dalam penelitian ini adalah sebagai berikut:

1) Studi pustaka: yaitu kegiatan menghimpun informasi yang relevan dengan topik atau masalah yang akan atau sedang diteliti, dari buku-buku ilmiah, laporan penelitian, karangan-karangan ilmiah, peraturanperaturan, ketetapan-ketetapan, jurnal, dan sumbersumber tertulis baik tercetak maupun elektroniklain.

2) Observasi: yaitu metode pengumpulan data melalui pengamatan langsung atau peninjauan secara cermat dan langsung di lapangan atau lokasi penelitian yaitu PT. Arista Jaya Lestari (Wuling Motors Serang).

3) Wawancara: wawancara ini bertujuan untuk mendapatkan informasi langsung dari pihak yang berwenang dan bertanggung jawab dalam meberikan data mengenai kerusakan kendaraan Wuling Confero $\mathrm{S}$

\section{B. Analisa Sistem Yang Berjalan}

Analisis sistem yang berjalan bertujuan untuk mengetahui lebih jelas bagaimana cara kerja sistem tersebut, sehingga kelebihan dan kekurangan sistem dapat diketahui.

Prosedur diagnosa kerusakan dilakukan ketika pemilik kendaraan membawa mobilnya ke bengkel resmi untuk ditangani oleh mekanik :

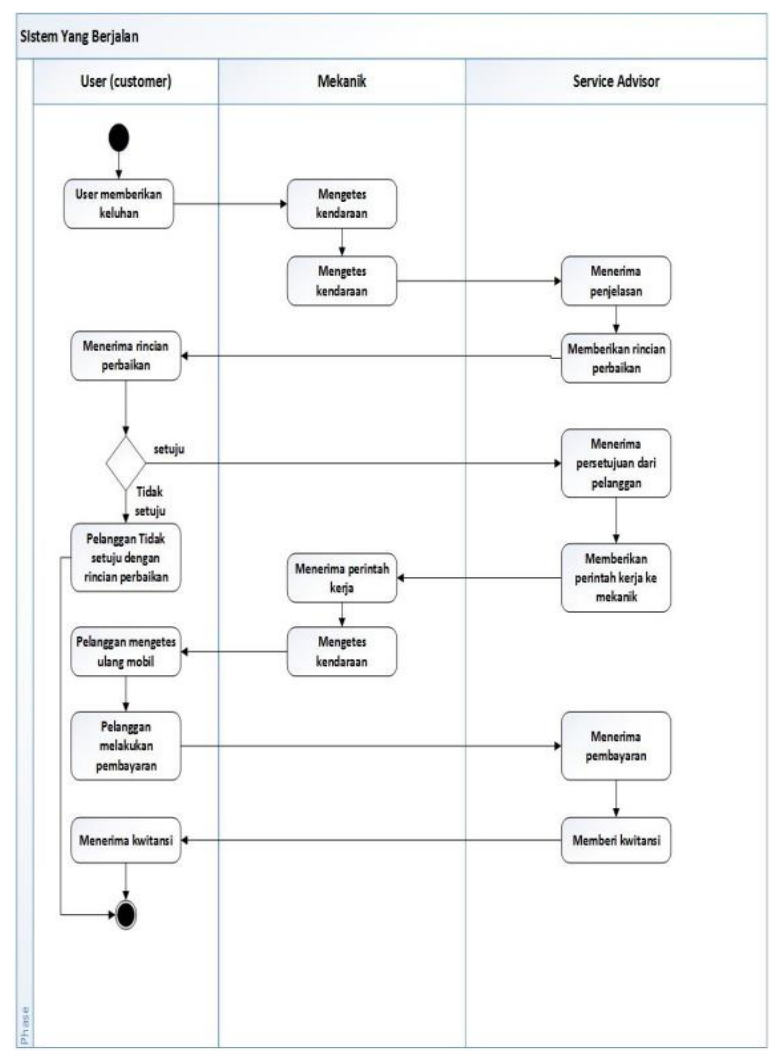




\begin{tabular}{ll} 
Hampir Pasti & 0,8 \\
Pasti & 1 \\
\hline
\end{tabular}

\section{Metode Certainty Factor}

Teori Certainty Factor mengakomodasi ketidakpastian pemikiran (inexact reasoning) seorang pakar. Seorang pakar (misalnya dokter) seringkali menganalisis informasi yang ada dengan ungkapan seperti "mungkin", "kemungkinan besar", "hampir pasti". Untuk mengakomodasi hal ini kita menggunakan certainty factor (CF) guna menggambarkan tingkat keyakinan pakar terhadap masalah yang sedang dihadapi dengan metode "Net beliefe yang diusulkan oleh E.H. Shortliffe dan B.G.Buchanan.

Formula Certainty Factor :

Certainty factor memperkenalkan konsep keyakinan dan ketidakyakinan yang kemudian diformulakan dalam rumusan dasar sebagai berikut:

Keterangan:

$$
\mathrm{CF}[\mathrm{H}, \mathrm{E}]=\mathrm{MB}[\mathrm{H}, \mathrm{E}]-\mathrm{MD}[\mathrm{H}, \mathrm{E}]
$$

$\begin{array}{lll}\mathrm{CF}[\mathrm{H}, \mathrm{E}] & : & \begin{array}{l}\text { certainty factor hipotesa yang } \\ \text { dipengaruhi oleh } \text { evidence e diketahui } \\ \text { dengan pasti. }\end{array} \\ \mathrm{MB}[\mathrm{H}, \mathrm{E}] & : \begin{array}{l}\text { measure of belief terhadap hipotesa } \mathrm{H}, \\ \text { jika diberikanevidence } \mathrm{E} \\ \text { (antara 0 dan 1) }\end{array} \\ \mathrm{MD} & : \quad \begin{array}{l}\text { Measure of Disbelief (Nilai } \\ \text { Ketidakpercayaan) }\end{array} \\ \mathrm{P} & : \begin{array}{l}\text { Probability } \\ \mathrm{E}\end{array} & : \text { Evidence (Peristiwa/Fakta) }\end{array}$

Certainty Factor untuk kaidah dengan premis/gejala tunggal (single premis rules):

$$
\mathrm{CF}_{\text {gejala }}=\mathrm{CF}[\mathrm{user}] * \mathrm{CF}[\text { pakar }]
$$

Certainty Factor untuk kaidah dengan premis/gejala lebih dari satu :

$$
\begin{aligned}
& \mathrm{CF}[\mathrm{A} \wedge \mathrm{B}]=\operatorname{Min}(\mathrm{CF}[\mathrm{a}], \mathrm{CF}[\mathrm{b}]) * \mathrm{CF}[\text { rule }](3) \\
& \mathrm{CF}[\mathrm{A} \vee \mathrm{B}]=\operatorname{Max}(\mathrm{CF}[\mathrm{a}], \mathrm{CF}[\mathrm{b}]) * \mathrm{CF}[\text { rule }](4)
\end{aligned}
$$

Apabila terdapat kaidah dengan kesimpulan yang serupa (similiary concluded rules) atau lebih dari satu gejala, maka CF selanjutnya dihitung dengan persamaan:

$$
\mathrm{CF}_{\text {combine }}=\mathrm{CF}_{\text {old }}+\mathrm{CF}_{\text {gejala }} *\left(1-\mathrm{CF}_{\text {old }}\right)
$$

Sedangkan untuk menghitung persentase terhadap penyakit, digunakan persamaan:

$$
\mathrm{CF}_{\text {persentase }}=\mathrm{CF}_{\text {combine }} * 100
$$

\begin{tabular}{|c|c|c|}
\hline Certainty Term & \multicolumn{2}{|c|}{ CF Akhir } \\
\hline Pasti Tidak & & $-1,0$ \\
\hline Hampir Pasti Tidak & $-0,8$ & \\
\hline Kemungkinan Besar Ti & idak & $-0,6$ \\
\hline Mungkin Tidak & & $-0,4$ \\
\hline Tidak Tahu/Tidak Yak & & $-0,2---0,2$ \\
\hline Mungkin & 0,4 & \\
\hline Kemungkinan Besar & 0,6 & \\
\hline
\end{tabular}

Untuk menentukan keterangan faktor keyakinan dari pakar, dilihat dari $\mathbf{C F}_{\text {combine }}$ dengan berpedoman dari tabel interpretasi (term) certainty factor berikut :

Tabel 1

Tabel Interprestasi Certainty Factor

\section{HASIL DAN PEMBAHASAN}

\section{A. Perhitungan Menggunakan Metode Certainty Factor (CF)}

Adapun langkah-langkah penyelesaian masalah dengan menggunakan metode Metode Certainty Factor (CF) dijelaskan sebagai berikut:

1) Tabel Data Kerusakan

Dalam pembuatan sistem pakar, langkah awal adalah menentukan kerusakan-kerusakan yang terjadi pada kendaraan:

Tabel 2

Tabel Data Kerusakan

\begin{tabular}{cl}
\hline Kode Kerusakan & \multicolumn{1}{c}{ Jenis kerusakan } \\
\hline K01 & Kampas kopling habis \\
K02 & Pompa bahan bakar rusak \\
K03 & Battery/Accu lemah \\
K04 & Koil rusak \\
K05 & Shock Absorber lemah \\
K06 & Kampas rem habis \\
K07 & Busi rusak \\
K08 & Mesin overheat \\
K09 & Bearing roda rusak \\
K10 & Mesin mengelitik/knocking \\
\hline
\end{tabular}

2) Tabel Diagnosa

Tabel diagnosa digunakan untuk membantu proses pemeriksaan terhadap kerusakan-kerusakan kendaraan :

Tabel 3

Tabel Diagnosa

\begin{tabular}{cl}
\hline Nama Kerusakan & \multicolumn{1}{c}{ Gejala Kerusakan } \\
\hline Kampas kopling & Akselerasi Habis, Pedal \\
habis & Kopling terasa berat, \\
& Kendaraan tidak ada tenaga, \\
& Jarak injak kopling pendek, \\
& Mesin tidak mati saat kopling \\
& dilepas tiba-tiba, Muncul bau \\
& gosong diarea depan, Saat \\
pindah gigi terasa keras. & Mesin mobil susah hidup, \\
Pompa bahan bakar & Akselerasi mesin terasa lebih \\
rusak & lambat, Mesin \\
& tersendat/brebet, Bau bahan \\
& bakar tercium menyengat. \\
Battery/Accu lemah & Mesin tidak bisa dihidupkan \\
& (starter), Lampu mobil tidak \\
& terang (redup), Suara klakson \\
& mulai tidak nyaring. \\
Koil rusak & Mesin tersendat/brebet, \\
& Muncul percikan api listrik \\
& dibadan koil, \\
& startermenjadi lebih lama, \\
& mesin mati mendadak saat \\
& putaran iddle.
\end{tabular}


Shock Absorber lemah

Busi rusak

Mesin overheat mengelitik/knocking

3) Tabel Matriks

Pembuatan tabel matriks untuk membantu dalam mengorganisasi pengetahuan kerusakan kendaraan agar lebih mudah dipahami.

Tabel 4

Tabel Matriks

\begin{tabular}{cc}
\hline $\begin{array}{l}\text { Gejala } \\
\text { [K9] [K10] }\end{array}$ \\
\hline G01 & X \\
G02 & X \\
G03 & X \\
G04 & X \\
G05 & X \\
G06 & X \\
G07 & X
\end{tabular}

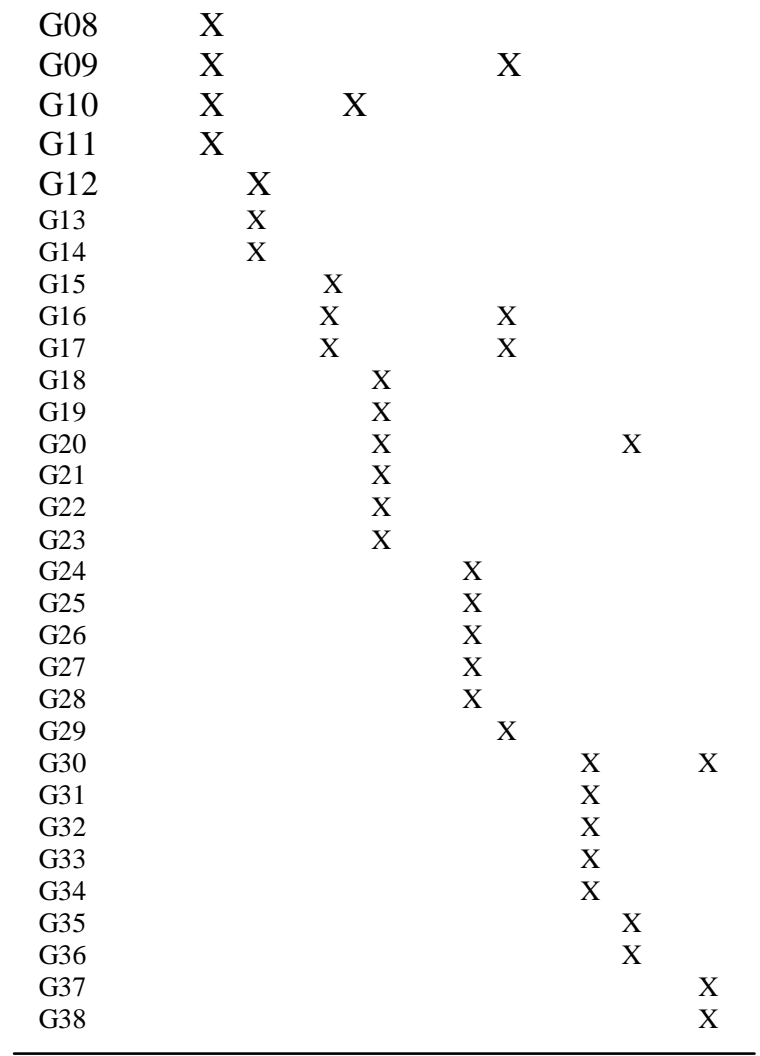

Keterangan gejala :

[G01] Akselerasi habis

[G02] Pedal kopling berat

[G03] Kendaraan tidak ada tenaga

[G04] Jarak injak pedal kopling pendek

[G05] Mesin tidak mati saat kopling dilepas tiba-tiba

[G06]Muncul bau gosong diarea depan

[G07] Saat pindah gigi terasa keras

[G08] Mesin mobil susah hidup

[G09]Akselerasi mesin terasa lebih lambat

[G10] Mesin nyendat/brebet

[G11] Bau bahan bakar menyengat

[G12] Mesin tidak bisa dihidupkan

[G13] Lampu mobil mulai tidak terang(redup)

[G14] Suara klakson tidak nyaring

[G15] Muncul percikan api listrik dibadan koil

[G16] Waktu starter menjadi lebih lama

[G17] Mesin mati mendadak saat iddle

[G18] Guncangan keras saat lewat jalan rusak

[G19] Mobil terasa tidak stabil saat jalan

[G20] Permukaan ban aus tidak merata

[G21] Keluar cairan pelumas pada shock absorber

[G22] Ada suara jedug saat lewat jalan rusak

[G23] Saat pengereman mobil terasa tidak stabil

[G24] Pedal rem terasa dalam saat diinjak

[G25] Saat jalan Pedal rem terasa getar saat diinjak

[G26] Muncul suara gesekan saat rem

[G27] Level minyak rem berkurang pada tangki

[G28] Ketebalan kampas rem menipis

[G29] Putaran mesin tidak halus

[G30] Tenaga mesin berkurang saat suhu mesin panas

[G31] Temperatur suhu menunjukkan diatas normal 
[G32] AC terasa panas

[G33] Performa mesin menurun

[G34] Oli bercampur dengan air

[G35] Timbul bunyi gemuruh pada area roda

[G36] Roda goyang dan oblak

[G37] Muncul suara ngelitik pada mesin

[G38] Timbul getaran mesin bersamaan suara ngelitik

4) Aturan Rule

Aturan rule merupakan kaidah aturan pada setiap gejala yang ditetapkan dalam proses perhitungan metode certainty factor, yaitu sebagai berikut :

Rule 01 (Kampas Kopling Habis) : IF G01 THEN K01

IF G02 THEN K01

IF G03 THEN K01

IF G04 THEN K01

IF G05 THEN K01

IF G06 THEN K01

IF G07 THEN K01

Rule 02 (Pompa Bahan Bakar) :

IF G08 THEN K02

IF G09 THEN K02

IF G10 THEN K02

IF G11 THEN K02

Rule 03 (Battery/Accu Lemah) :

IF G12 THEN K03

IF G13 THEN K03

IF G14 THEN K03

Rule 04 (Koil Rusak) :

IF G10 THEN K04

IF G15 THEN K04

IF G16 THEN K04

IF G17 THEN K04

$\mathbf{R}$
Rule 05 (Shock Absorber Lemah) :

IF G18 THEN K05

IF G19 THEN K05

IF G20 THEN K05

IF G21 THEN K05

IF G22 THEN K05

IF G23 THEN K05

Rule 06 (Kampas Rem Habis) :

IF G24 THEN K06

IF G25 THEN K06

IF G26 THEN K06

IF G27 THEN K06

IF G28 THEN K06

Rule 07 (Busi Rusak) :

IF G09 THEN K07

IF G16 THEN K07

IF G17 THEN K07

IF G29 THEN K07

Rule 08 (Mesin Overheat) :

IF G30 THEN K08

IF G31 THEN K08

IF G32 THEN K08

IF G33 THEN K08

IF G34 THEN K08

\author{
Rule 09 (Bearing Roda Rusak) : \\ IF G20 THEN K09 \\ IF G35 THEN K09 \\ IF G36 THEN K09 \\ Rule 10 (Mesin Mengelitik) : \\ IF G30 THEN K10 \\ IF G37 THEN K10 \\ IF G38 THEN K10
}

Untuk menentukan keterangan faktor keyakinan dari pakar, dilihat dari CFcombine dengan berpedoman dari tabel interpretasi (Term) certainty factor. Adapun tabel tersebut dapat dilihat sebagai berikut:

Tabel 5

Tabel interpretasi

\begin{tabular}{ccc}
\hline No & Certainty Term & CF $_{\text {akhir }}$ \\
\hline 1 & Tidak & 0 \\
2 & Tidak Tahu & 0.2 \\
3 & Sedikit Yakin & 0.4 \\
4 & Cukup Yakin & 0.6 \\
5 & Yakin & 0.8 \\
6 & Sangat Yakin & 1 \\
\hline
\end{tabular}

Pada sesi diagnosa kerusakan, user diberikan pilihan interpretasi yang masing masing memiliki nilai $\mathrm{CF}$ sebagai berikut :

Tidak

0

Tidak tahu

0,2

Sedikit Yakin

0,4

Cukup Yakin

0,6

Yakin

0,8

Sangat Yakin

1

5) Analisis Perhitungan Metode

Pada tahap ini menjelaskan proses perhitungan metode certainty factor dengan data real dari user dan pakar.

Sebagai contoh berikut pehitungan untuk kerusakan (K01) Kampas Kopling Habis dengan gejala yang telah dipilih oleh user beserta nilai kepercayaannya. . Langkah pertama, pakar menentukan nilai CF dari setiap gejala sebagai berikut.

CF Pakar G01(Akselerasi habis)

$=\mathrm{MB}-\mathrm{MD}$

$=1-0=1$

CF Pakar G02(Pedal kopling berat)

$=\mathrm{MB}-\mathrm{MD}$

$=0.8-0.2=0.6$

CF Pakar G03 (Kendaraan tidak ada tenaga)

$=\mathrm{MB}-\mathrm{MD}$

$=1-0.2=0.8$

CF Pakar G04 (Jarak injak pedal kopling pendek)

$=\mathrm{MB}-\mathrm{MD}$

$=0.6-0.2=0.4$

CF Pakar G05(Mesin tidak mati saat kopling dilepas tiba-tiba)

$=\mathrm{MB}-\mathrm{MD}$

$=1-0.2=0.8$ 
CF Pakar G06 (Muncul bau gosong diarea depan)

$=\mathrm{MB}-\mathrm{MD}$

$=0.8-0.2=0.6$

CF Pakar G07 (Saat pindah gigi terasa keras)

$=$ MB-MD

$=0.8-0.2=0.6$

Kemudian nilai $\mathrm{CF}$ dihitung dengan menggunakan persamaan di bawah ini.
$\mathrm{CF}$ gejala $=\mathrm{CF}($ user $) * \mathrm{CF}($ pakar $)$
$\mathrm{CF} 1.1=0.6 * 1 \quad=0.6$
$\mathrm{CF} 1.2=0.6 * 0.6=0.36$
$\mathrm{CF} 1.3=0.8 * 0.8=0.64$
$\mathrm{CF} 1.4=0.4 * 0.4 \quad=0.16$
CF $1.5=0.4 * 0.8 \quad=0.32$
$\mathrm{CF} 1.6=1 * 0.6 \quad=0.6$
$\mathrm{CF} 1.7=0.6 * 0.6=0.36$

Dikarenakan terdapat lebih dari satu gejala, maka untuk menentukan CF Kerusakan selanjutnya digunakan persamaan (2)

CFcombine $1(\mathrm{CF} 1, \mathrm{CF} 2)=\mathrm{CF} 1+\mathrm{CF} 2 *(1-\mathrm{CF} 1)$

Sehingga menjadi :

CFcombine1 $(\mathrm{CF} 1,1, \mathrm{CF} 1.2)=0.6+0.36 *(1-0.6)$

$$
\begin{aligned}
& =0.6+0.144 \\
\text { CFold } 1 & =0.744
\end{aligned}
$$

C CFcombine2(CFold1,CF1.3) $=0.744+0.64 *(1-0.744)$

$$
\text { CFold } 2=0.9078
$$

C CFcombine3(CFold2,CF1.4) $=0.9078+0.16 *(1-0.9078)$

$$
=0.9078+0.0147
$$

CFold $3=0.9225$

CFcombine4(CFold3,CF1.5) $=0.9225+0.32 *(1-0.9225)$

$$
=0.9225+0.0248
$$

CFold4 $=0.9473$

CFcombine5(CFold4,CF1.6) $=0.9473+0,6 *(1-0,9473)$

$$
=0.9473+0.0316
$$

CFold5 $=0.9789$

CFcombine6 $($ CFold5,CF1.7) $=0.9789+0.36 *(1-0.9789)$

$$
=0.9789+0.0076
$$

CFold6 $=0.9865$ (CF akhir)

Untuk mendapatkan nilai dalam bentuk persentase, maka menggunakan rumus $\mathrm{CF}$ Persentase sebagai berikut :

$\mathrm{CF}$ persentase $=\mathrm{CF}_{\text {old } 6} \times 100$

$$
\begin{aligned}
& =0,9865 \times 100 \\
& =98,65 \%
\end{aligned}
$$

Dari hasil persentase tersebut dapat disimpulkan bahwa faktor kepastian seorang user yang telah melakukan kuisioner diagnosa terhadap jenis kerusakan kampas kopling habis adalah sebesar $98,65 \%$.

\section{B. Perancangan Sistem}

Perancangan sistem dalam penelitian ini menggunakan diagram use case. Berikut rancangan diagram use case sistem:

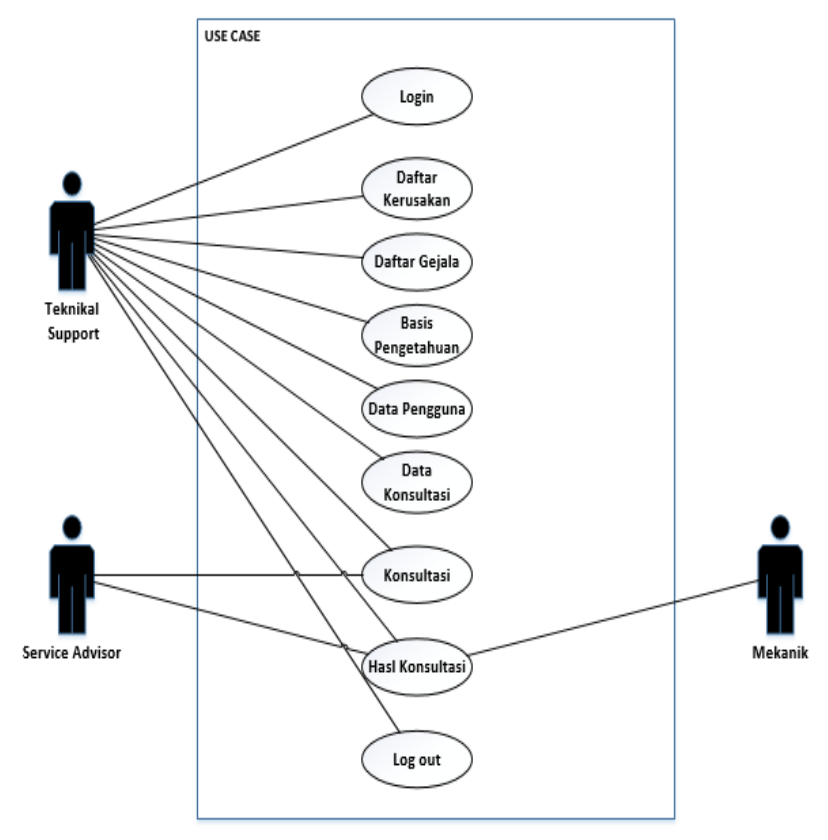

Gambar 3. Diagram Use Case Sistem

C. Implementasi User Interface

Berikut implementasi dari tampilan user interface dari sistem pakar :

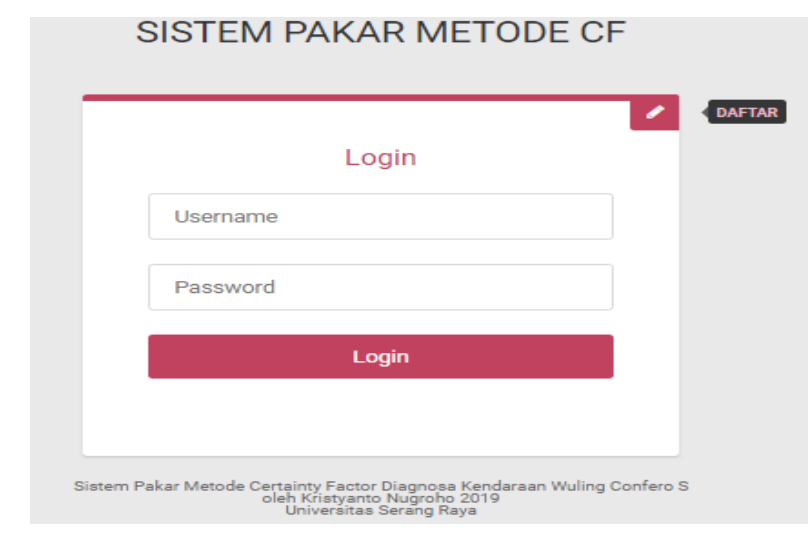

Gambar 4. Tampilan Halaman Login
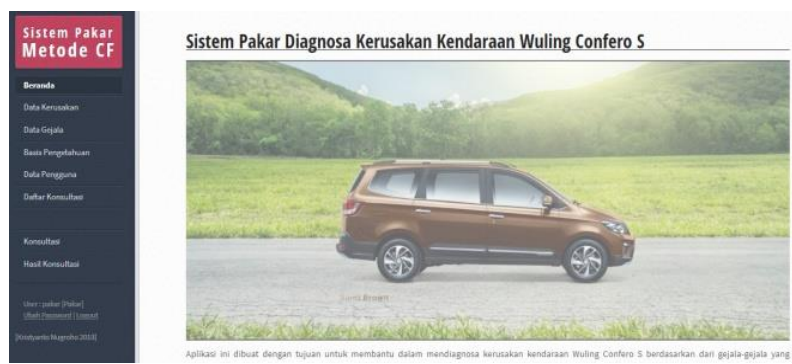

Gambar 5. Tampilan Halaman Utama 


\section{KESIMPULAN}

Aplikasi yang dibuat ini menghasilkan output berupa jenis kerusakan serta gejala yang timbul dan juga menampilkan presentase kerusakannya.

Aplikasi sistem pakar ini menggunakan perhitungan metode certainty factor, dimana nilai keyakinan dari pakar akan dibandingkan dengan nilai keyakinan dari user sehingga akan diperoleh nilai kepastian diagnosa sesuai kaidah perhitungan metode certainty factor.

\section{REFERENSI}

[1] Hengki Tamando Sihotang. (2014)“Jurnal Sistem Pakar Mendiagnosa Penyakit Kolesterol Pada Remaja Dengan Metode Certainty Factor Berbasis Web".Program Studi Teknik Infotmatik, STMIK Pelita Nusantara Medan. Jusuf Wahyudi, Juju Jumadi

[2] Khairina Eka Setyaputri , Abdul Fadlil , dan Sunardi (2018). "Jurnal Analisis Metode Certainty Factor pada Sistem Pakar Diagnosa Penyakit THT." Program Studi Magister Teknik InformatikaUniversitas Ahmad Dahlan, Yogyakarta, Indonesia

[3] RikaRosnelly. (2011). "Sistem Pakar Konsep dan Teori"..Yogyakarta.

[4] Stephanie Halim, Seng Hansun. (2015) “Jurnal Penerapan Metode Certainty Factor dalam Sistem Pakar Pendeteksi Resiko Osteoporosis dan Osteoarthritis".Program Studi Teknik Informatika, Universitas Multimedia Nusantara, Tangerang,

[5] Sutarman. (2012). "Buku Pengantar Teknologi Informasi”. Jakarta: Bumi Aksara

[6] YM Kusuma. (2012). PHP Menyelesaikan Website 30 Juta. Jakarta: Jasakom. 